\title{
Beobachtungen über den Röhrenbau von Lanice conchilega (PALLAS) im Experiment und am natürlichen Standort
}

\author{
Von Erich Ziegelmeier \\ Biologische Anstalt Helgoland, List auf Sylt \\ Forschungsinstitut der Bundesanstalt für Fischerei \\ (Mit 9 Abbildungen)
}

Inhaltsübersicht

\begin{abstract}
A. Einleitung Seite 107 - B. Die Lanice-Wohnröhre S. 108 - I. Herstellung der Röhre S. 108 - II. Baumaterial S. 112 - III. Die Lanice- ${ }_{n}$ Bäumchen “ und deren Bedeutung für den Nahrungserwerb S. 112 - IV. Stodkwerkbildung der Fransenkronen S. 112 - C. Experimente und Einzelbeobachtungen im Aquarium S. 115 - I. Die über der Bodenoberfläche ragenden Röhrenenden und die Stodkwerkbildung S.115 - II. Das Bauen im Sediment S.118 III. Die U-Röhre S. 120 - D. Beobachtungen am natürlichen Standort S. 123 - I. Vorkommen von Lanice S. 123 - II. Riffartige Lanice-Polster am Sylter Ellenbogen-Nordstrand S. 126 - E. Auswertungsmöglichkeiten der Beobachtungsergebnisse S. 127 - F. Zusammenfassung S. 127 - G. Literatur S. 128.
\end{abstract}

\section{A. Einle itung}

Mannigfach sind die Pläne und Prinzipien, nach denen eine Reihe, von marinen, sedentären Borstenwürmern ihre Wohnröhren und -gänge in den verschiedenen Sedimentarten des Meeresbodens bauen. Ihre genaue Kenntnis trägt zur Erforschung der Lebensweise dieser Würmer wesentlich bei und ist für die Klärung vieler biologischer und ökologischer Fragen unbedingt erforderlich. Besonders auffällig und zu Beobachtungen anregend ist die Wohnröhrenbauweise von Lanice conchilega, einer im Litoral mitunter dicht siedelnden Terebellide. Troţ ihres häufigen Vorkommens in dem Meeresgebiet, das durch die Gezeiten eine direkte Beobachtung auf den trockengefallenen Wattböden gestattet, sind unsere Kenntnisse über den Röhrenbau und die Biologie von Lanice aber noch lückenhaft. Der Zweck der vorliegenden Untersuchung ist, mit Hilfe von Experimenten und durch Beobachtungen am natürlichen Standort zur Beantwortung einiger Fragen beim Wohnröhrenbau und der Lebensweise von Lanice conchilega beizutragen ${ }^{1}$ ).

1) Herrn Prof. Hagmeier danke ich an dieser Stelle für seine Hinweise und Ratschläge während der Untersuchungen. 


\section{B. Die Lanice-Wohnröhre}

Die Wohnröhre von Lanice conchilega besteht aus einer inneren häutigen Schicht, auf die außen eine Lage harter Bodenbestandteilchen verschiedenster Herkunft und Größe gekittet ist. Die in ihrer Struktur gleichförmig und mattglasig durchscheinende Grundschicht der Röhre stellt der Wurm aus Schleim her, der von den auf der Ventralseite der vordersten Segmente, den Bauchschildern (siehe Abb. 1) befindlichen Drüsenpaaren ausgeschieden wird und im Wasser erhärtet. Die biegsame Röhre steht senkrecht im Boden und ragt mit ihrem oberen, mit Fransen besetzten Ende, für das die Bezeichnung Lanice"Bäumchen" angewandt wird, im Durchschnitt 20-30 mm über die Bodenoberfläche. Nach Beobachtungen von KöNIG (1949) baut Lanice U-förmige Wohnröhren, wobei zwei Bäumchen über der Oberfläche errichtet werden. Der Wurm kann auf diese Weise seine Tentakeln aus der einen oder anderen Röhrenöffnung herausstrecken, um Nahrung und Baumaterial hereinzuholen. SeILACHER (1951) fand neben der U-Röhre den W-förmigen Bau, den er mit dem Wachstum von Lanice in Zusammenhang bringt. Ob diese Annahme von SEILACHER zutrifft, oder ob Lanice während des Wachstums die alte Wohnröhre in bestimmten Zeitabständen verläßt, um eine neue, ihrer Größe entsprechende Röhre zu bauen, sich also gewissermaßen "häutet“, sollen Untersuchungen über die Entwicklung von Lanice klarstellen, mit denen bereits während der Versuche und Beobachtungen für die vorliegende Darstellung begonnen wurde. Auf die Frage, wie weit die Beobachtungen in den von KöNIG und SeILACHER untersuchten Standorten eine Verallgemeinerung zulassen, nach der die U-förmige Wohnröhrenbauweise bei Lanice als "Norm" zu betrachten ist, wird in der vorliegenden Mitteilung noch näher einzugehen sein. Neuere Angaben über die Lanice-Röhre finden sich bei Eales (1950), WiLSON (1950) und YoNGE (1949).

\section{Herstellung der Röhre}

Zum Verständnis der Tätigkeit beim Bau der Röhre und der Fransenkrone seien einige Bemerkungen über die Morphologie des Kopfabschnittes von Lanice vorausgeschickt (s. Abb. 1):

Der Kopflappen (Prostomium) hat sich zu der vorspringenden, löffelartigen Oberlippe entwickelt, die ihre Gestalt stark verändern kann und beim Bauvorgang eine wichtige Rolle spielt. Am Prostomium sitgen die zahlreichen Tentakeln. Als Unterlippe schließt sich hinter der Mundöffnung das Buccalsegment an, das aus der Verschmelzung des Metastomiums mit dem ersten Körpersegment entstanden ist und an der Ausbildung von zwei, etwas ventral verschobenen, dreieckigen Lappen zu erkennen ist. Das zweite Körpersegment ist kurz und trägt auf der Dorsalseite das vorderste und kräftigste Kiemenpaar. Mit zwei seitlichen Lappen und zwei Kiemen versehen ist das dritte Segment. Es folgt das borstentragende vierte Segment (ohne Hakenborsten, die erst am fünften Segment beginnen) mit den beiden hintersten Kiemen.

Bei der Fertigstellung der Lanice-Wohnröhre müssen drei Bauvorgänge unterschieden werden, die sich in den dabei vom Wurm angewandten Methoden voneinander unterscheiden: 1. die Herstellung des Röhrenschaftes im Boden, 2. der Bau des über den Sand ragenden Röhrenstückes (Stammteil des Bäumchens) und 3. das Aufsetzen der Fransen.

Beim Bauen des Röhrenschaftes im Boden fügt Lanice das Material nicht 
aktiv ein, sondern die umliegenden Bestandteile des Sediments kleben auf der vom Wurm ausgeschiedenen Schleimhülle, der Grundschicht der Röhre, fest. Auf diese Röhrenbauweise im Sediment wird bei der Darstellung der Aquariumsbeobachtungen noch näher eingegangen (S. 118).

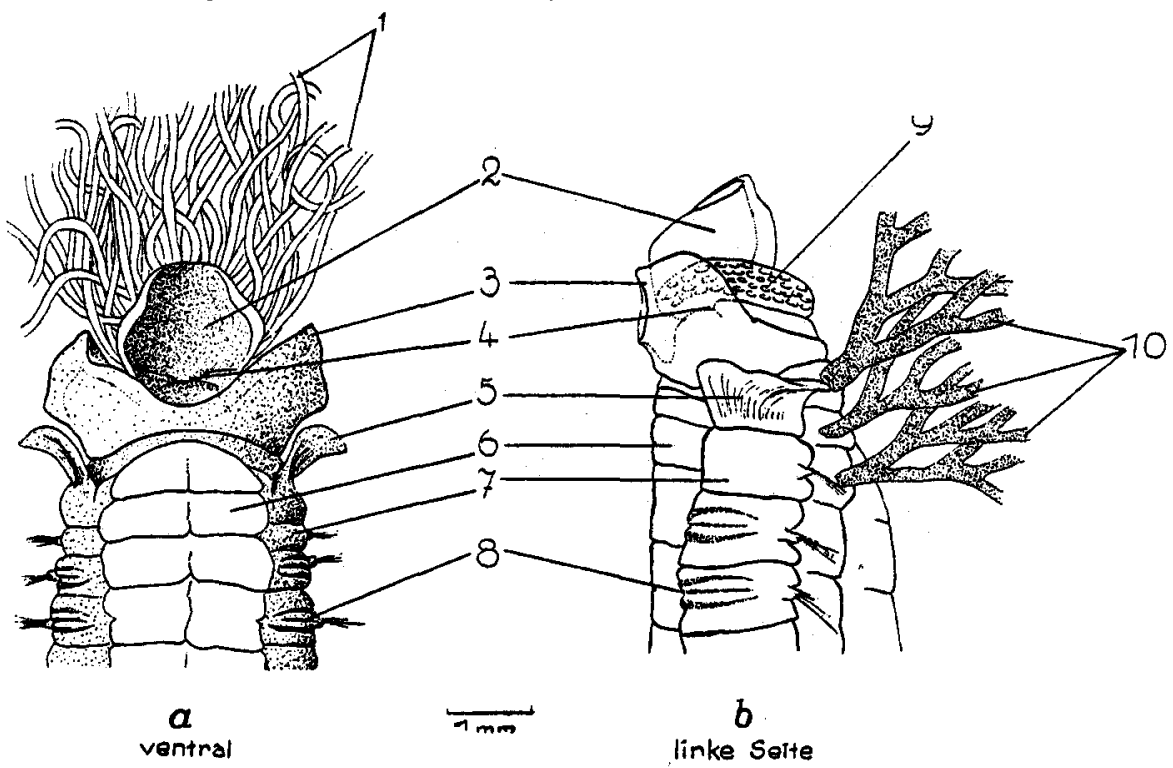

Abb. 1:

Kopfabschnitt und vordere Körpersegmente von Lanice conchilega, nach dem lebenden Tier gezeichnet.

a) Ventralansicht,

b) dasselbe Tier von der linken Seite.

$1=$ Tentakeln; $2=$ Prostomium (Oberlippe); $3=$ die ventralwärts verschobenen Lappen (Unterlippe) des Buccalsegments; $4=$ Mundöffnung; $5=$ die seitlichen Lappen des dritten Körpersegments; $6=$ die vorderen der 14 bis 20 Bauchschilder, die, zum Teil undeutlich voneinander getrennt, zu einem etwas erhabenen Band verschmolzen sind, das vorn abgerundet ist und im hinteren Abschnitt des thorakalen Teiles des Wurmkörpers spitz ausläuft; $7=$ das vierte Körpersegment, das nur Haarborsten und keine Hakenborsten trägt; $8=$ Hakenborstenreihe; $9=$ Ansatzstellen der Tentakeln am Prostomium; $10=$ die dichotom-verzweigten Kiemen am zweiten, dritten und vierten Körpersegment.

Bei b) sind nur die linken Kiemen der drei Paare dargestellt und die feineren Verästelungen fortgelassen. Ferner ist in der Seitenansicht das Prostomium, die Lage der Mundöffnung und die vor dieser von den beiden Lappen des Buccalsegments und deren ventralem Verbindungsstüdk gebildeten Grube punktiert eingezeichnet.

Eine sehr gute Schilderung des Vorganges beim Bau des über den Sand ragenden Röhrenendes und der Fransenkrone gibt WATson (1890) in einer Darstellung, die der exakten Beobachtungsweise, der Deutung seiner Untersuchungsergebnisse und nicht zuletgt seiner klaren und übersichtlichen Handzeichnungen wegen (Abb. 2) besondere Beachtung verdient ${ }^{2}$ ).

Nach Watson baut Lanice über dem Boden in der folgenden Weise: Mit den zahlreichen, lang ausdehnbaren und mit Schleimdrüsen ausgestatteten Tentakeln wird das Baumaterial eingebracht. Der Querschnitt der Tentakeln

2) Leider wird diese Arbeit in den späteren Veröffentlichungen nur ganz selten zitiert, was wohl darin begründet zu sein scheint, daß WATson über die röhrenbauende Terebella littoralis berichtet, wobei es sich aber um Lanice conchilega handelt, wie auch die Synonyme bei McINTOSH (1922) und FAUvel (1927) eindeutig zeigen. 


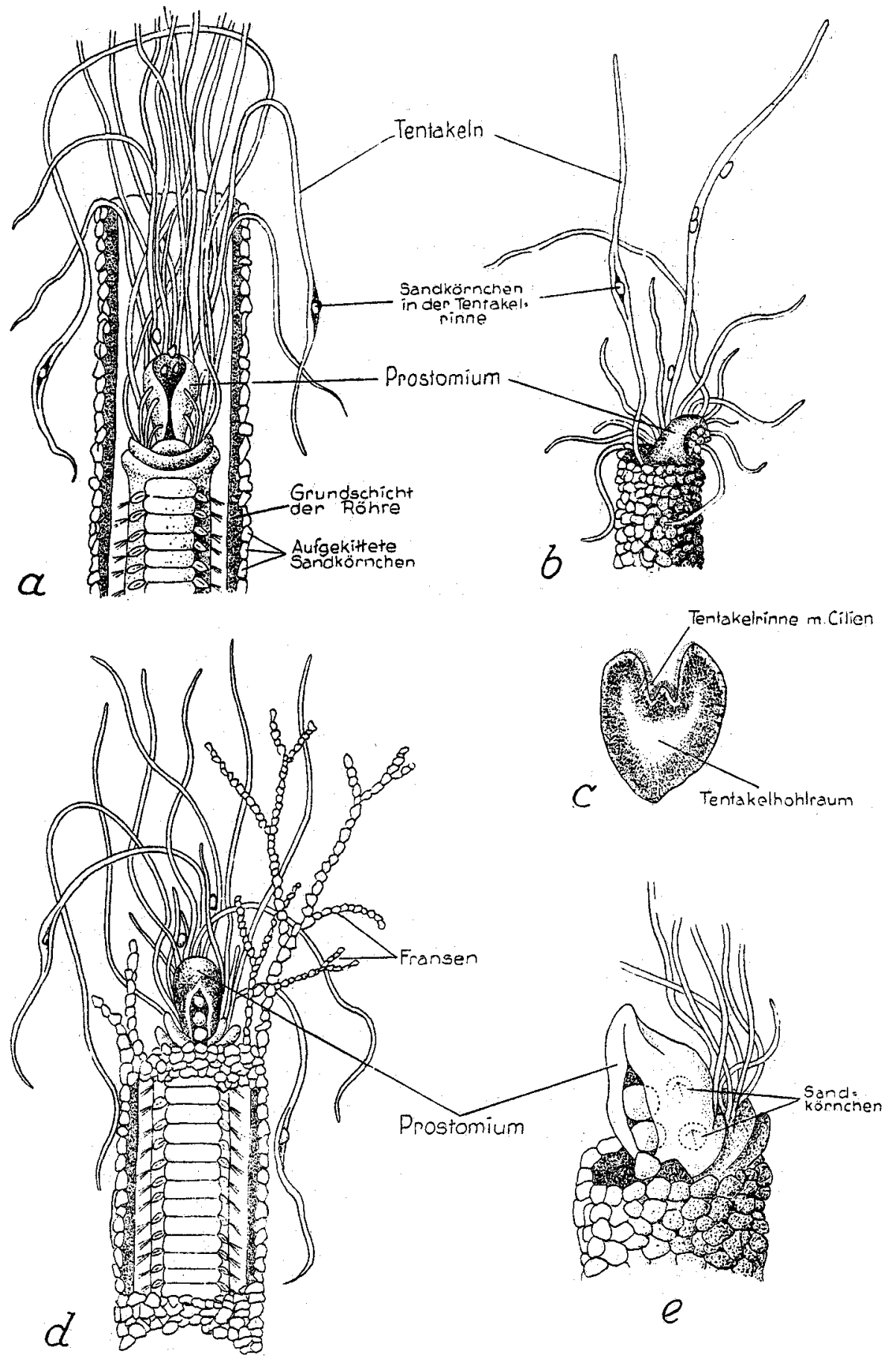

Abb. 2:

Lanice conchilega beim Bau der Röhre und der Fransenkrone (nach WATson).

$\mathrm{Da}$ es sich bei den Abbildungen von Watson um Beobachtungsskizzen handelt, die vermutlich schnell angelegt werden mußten, sind die vorderen Körpersegmente etwas schematisiert dargestellt worden und entsprechen zum Teil nicht den wirklichen morphologischen Verhältnissen (vgl. Abb. 1), was den Wert der WAtson'schen Skizzen aber in keiner Weise 
ist herzförmig, die der Mundöffnung zugekehrten beiden Längskanten und die von ihnen gebildete Mittelrinne sind mit Cilien bedeckt (Abb. 2c). Die beiden Kanten können zusammengefaltet werden, so daß ein Hohlzylinder oder ein halbzylindrischer Kanal entsteht. Der Transport von Bauteilchen geschieht entweder durch gerichteten Cilienschlag, durch eine Art von peristaltischen Bewegungen oder durch plötliche Kontraktion der Tentakeln. Am Kopfabschnitt übernehmen einige ganz kurze Tentakeln das eingebrachte Material und führen es der Oberlippe zu, die sich nach den Sandkornchen ausstreckt, wie (nach einem Vergleich von WATSON) ein Elefant seinen Rüssel beim Tränken benutt. Wenn genügend Material gesammelt ist, rollt sich das Prostomium über dem Mund ein, und die Bauteilchen werden mit Schleim vermischt. Danach beugt sich der Wurm über den freien, oberen Röhrenrand und baut das Material ein (Abb. 2a und 2b).

Watson sagt nichts über die Herkunft des Schleims. Es bleibt aber nur die Möglichkeit, daß der von den Drüsen der Bauchschilder stammende und auch für die Grundschicht der Röhre verwandte Schleim durch peristaltische Bewegungen des Wurmes zum Prostomium gelangt. Es ist anzunehmen, daß die Unterlippe (das Buccalsegment), die mit ihren beiden Lappen und deren ventralem Verbindungsstück eine Grube vor der Mundöffnung bildet, und das lateral zweilappige, dritte Körpersegment beim Heranführen des Schleims eine Rolle spielen.

Der Bau der Fransen geht in der Weise vor sich, daß die Oberlippe, nachdem ein großer Vorrat von Sandkörnchen auf die besprochene Art eingebracht und mit dem Schleim vermischt worden ist, ihre Gestalt so formt, daß auf der ventralen Seite nur ein schmaler Spalt offen bleibt (Abb. 2d und 2e). Das Tier kommt nun langsam aus der Röhre heraus und setzt ein Teilchen auf das andere, wobei die unteren von den Rändern der Lippenspalte so lange gehalten werden, bis sich der Schleim erhärtet. Nachdem das leţte Sandkörnchen gesetgt und der Vorrat verbraucht ist, zieht sich der Wurm blitsschnell in die Röhre zurück. Watson gibt für die Dauer des Vermauerns einer Prostomiumfüllung 5-10 Sekunden an. Die Linienführung der Fransen kommt durch die Haltung des Körpers zustande. Seeigelstacheln, Muschelbruchstückchen und andere Teile werden einzeln eingebaut.

schmälert. Die dorsal stehenden drei Kiemenpaare sind in sämtlichen Zeichnungen fortgelassen worden. Die in den Röhrenlängsschnitten bei a) und b) eingezeichnete Grundschicht ist in Wirklichkeit bedeutend dünner.

a) Ventrale Ansicht des vorderen Endes von Lanice in der Wohnröhre, die in einem Längsschnitt gezeichnet ist. Der Wurm sammelt mit den Tentakeln Sandkörnchen und befördert sie zum Prostomium (Oberlippe), das sich zu einem Trichter geformt hat.

b) Das Prostomium setzt die mit Schleim vermischten Sandkörnctien auf den oberen Rand der Röhre.

c) Querschnitt durch einen Tentakel.

d) Lanice beim Bau der Fransenkrone. Die Röhre ist am oberen und unteren Ende des dargestellten Stückes vollständig, dazwischen im Längsschnitt gezeichnet. Mit der zu einer Art Kapuze geformten Oberlippe (Prostomium), bei der ventral nur en so breiter Spalt offen bleibt, daß die Sandkörnchen gerade von dem den Spalt bildenden Lippenrand gehalten werden können, baut der Wurm die einzelnen Fransen, wie in

e) die laterale Ansicht des Kopfabschnittes zeigt. Die von den Tentakeln eingebrachten, im Prostomium gesammelten und mit Schleim vermischten Sandkörnchen werden in der punktiert eingezeidneten Weise im Prostomium so an den Spalt herangeführt, daß beim langsamen Aufsteigen des Wurmes in der Röhre ein Körnchen auf das andere gesetzt wird. 


\section{Baumaterial}

Als Baumaterial für den zur Verfestigung auf die häutige Grundschicht gekitteten äußeren Mantel der Röhre werden neben Sandkörnchen auch Muschel- und Schneckenschalenbruchstücke, von kleineren Tieren ganze Klappen oder Gehäuse, ferner Stacheln und Panzerteile von Echinocardium, Bruchstücke von Pectinaria-Röhren, Foraminiferen, Ostracodenschalen u. a. vom Wurm aktiv eingemauert oder kleben im Sediment auf der Grundschicht fest. Die häufig an der Röhrenwand festgeklebten größeren Steinchen, deren Durchmesser ein Mehrfaches der Röhrendicke betragen, und die fast erhaltenen Schalen von Muscheln sprechen ebenfalls für die Richtigkeit der Erklärung des Bauvorganges im Boden, da kaum anzunehmen ist, daß sie von den Würmern aktiv eingebaut worden sind. Auffällig ist auch, daß in der Nähe der Fransen keine derart großen Bauteilchen beobachtet werden können. Nach genauer Untersuchung zahlreicher Röhren treffen die Würmer keine Wahl in Größe und Zusammensebung des Materials für den Röhrenschacht und die aufsitenden Fransen, wie CASPERS (1938) angibt. Röhren und Bäumchen stellen geradezu eine Sammlung der Bestandteile des von Lanice bewohnten Sediments dar, die im Boden auf die Grundschicht der Röhre gekittet und auf der Oberfläche von den Tentakeln eingebracht werden.

III. Die Lanice-Bäumchen und deren Bedeutung für den Nahrungserwerb

Das für Lanice charakteristische, mit einer bäumchenartigen Fransenkrone beseţte, obere Röhrenende und das Bestreben der Würmer, bei Verlust, Sandüberdeckungen oder sonstigen schädigenden Umwelteinflüssen, die Bäumchen sofort wieder neu zu bauen und intakt zu halten, legen die Frage nach der Bedeutung, die sie für den Wurm haben, nahe. HAGMEIER (1927) berichtet, daß Lanice, nach Aquariumsbeobachtungen, mit Vorliebe kleine Planktontiere mit den langen Tentakeln aus dem freien Wasser fischt. Watson (1890) führt jedoch als erste und naheliegendste Erklärung an, daß dieses mit Fransen besetzte obere Röhrenende im Dienst des Nahrungserwerbs steht und wie ein "Stellnet" ${ }^{\text {) }}$ (nach Watson: "They may act as snares to catch food ") Nahrungsteilchen aus dem über dem Boden strömenden Wasser, das oft große Mengen von aufgewirbelten, Lanice als Nahrung dienenden Bodenbestandteilen mitführt, festhält. WATsON konnte bei seinen Versuchen öfter beobachten, daß die Lippen und die Tentakeln an den Astchen entlangstreichen. Eigene Aquariumsbeobachtungen bestätigen die Annahme W Arsons und lassen erkennen, daß seine zweite Deutung, nach der die Ästchen Stützen bilden (sie können demnach mit "Angelruten" verglichen werden), von denen aus das Tier mit seinen (bei größeren Würmern bis etwa $12 \mathrm{~cm}$ ausdehnbaren) Tentakeln den Boden der Umgebung nach Nahrung abweiden und Baumaterial heranschaffen kann, in Verbindung mit der ersten, den eigentlichen Sinn und Zweck der Bäumchen darstellen.

\section{Stockwerkbildung der Fransenkronen}

Den Anlaß zu den vorliegenden Untersuchungen gaben Beobachtungen an ausgedehnten, dichten Lanice-Siedlungen, die sich längs des Sylter Ellen-

3) Der von Serlacher angewandte Vergleich der Fransenkrone mit einer ,Reuse ${ }^{4}$ ist nicht gut gewählt, da es sich bei einer Reuse um einen konisch gebauten Netzschlauch handelt, während die bei Lanice meist in zwei Lappen angeordneten Fransenbüschel, über deren Anordnung und Herstellung bereits WArsoN (1890) eingehend berichtet hatte, eher einem Stellnetz gleichkommen. 
bogen-Nordstrandes (vgl. die Karte bei Kornmann, dieser Bd. S. 56) unterhalb der MTnW-Linie hinziehen und riffartige Polster (Abb. 3) bilden. Bei

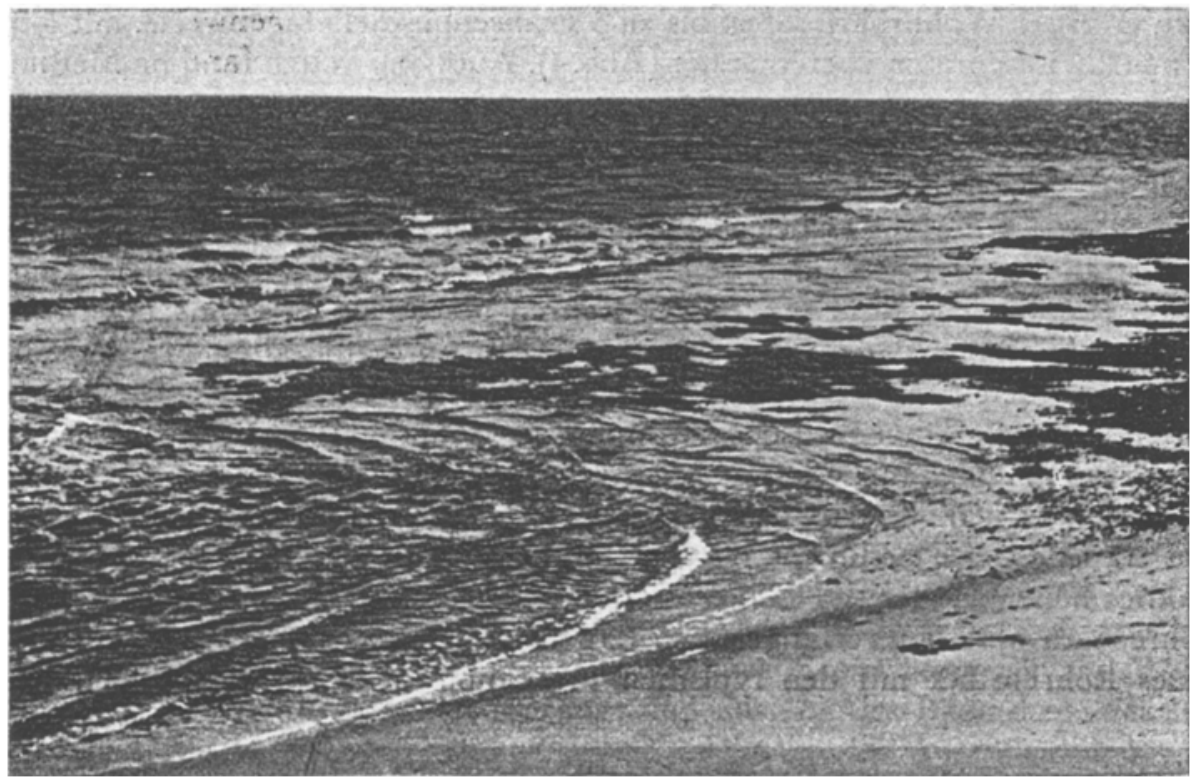

Abb. 3a.

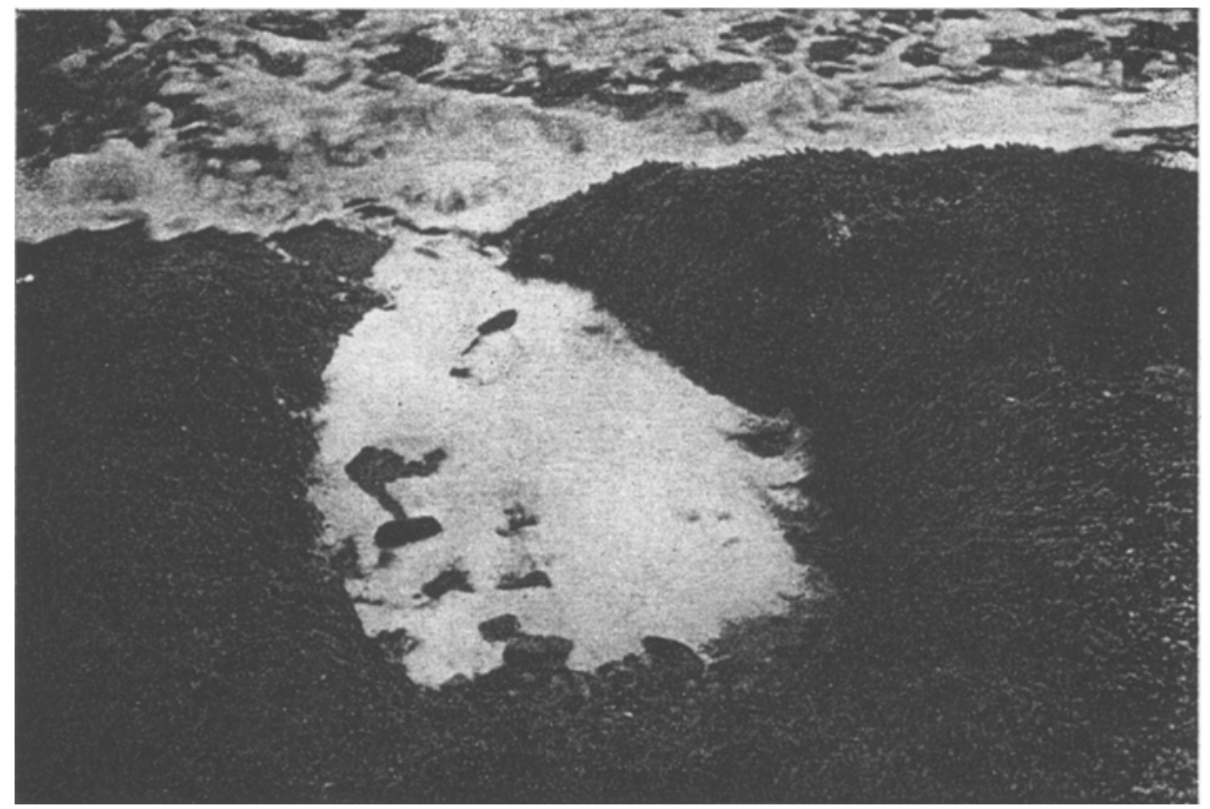

Abb. 3b.

Abb. 3. Bei sehr niedrigem Wasserstand (nach anhaltendem Ostwind im Oktober 1950) trockengefallene Teile der riffartigen Lanice-Polster am Sylter Ellenbogen-Nordstrand zwischen der 2. und 3. Buhne in der Nähe der Ostspitze.

a) Höher liegende Teile bei auflaufendem Wasser.

b) Ausschnitt aus einem tiefer liegenden Polster, das den dichten Bestand mit Wohnröhren zeigt.

(Verf. phot.)

8 Meeresuntersuchungen Bd. IV. H. 2 
einer großen Anzahl von Lanice-Wohnröhren, die im Oktober 1950 aus den Polstersiedlungen gegraben oder am Strand angespült gefunden wurden, fiel auf, daß sie am oberen Röhrenende nicht nur eine Ästchenkrone hatten, sondern an einer Wohnröhre saßen bis zu 5 Fransenbüschel etagenweise, mit 5 bis $10 \mathrm{~mm} Z$ wischenraum übereinander (Abb.4). Auch SEII.ACHER fand im Mellumwatt „alte Mündungstrichter, welche oft zu mehreren übereinander wie Halskrausen den Schacht umgeben ". Diese Stodkwerkbildungen bei Lanice-Röhren sind nach einer Mitteilung von Herrn Prof. HAGMEIER schon früher festgestellt worden, wie eine Notiz über einige Jahre zurüdkliegende Beobachtungen am Nordstrand vom Ellenbogen zeigt, nach der ,bei tiefen TnW dort kleine Hügel standen, die dicht mit Lanice-Röhren besetgt waren" und "beim sorgfältigen Abgraben der Lanice-Hügel mehrere, durch die alten Fransenköpfe gekennzeichnete Stodkwerke der Wohnröhre gefunden“ wurden. Die Hügelbildung und die etagenweise Anordnung der Fransenkrone stehen in ursächlichem Zusammenhang. Die mit Lanice dicht bestandenen Flecken, die wie ein Sandfang wirken, halten das durch Brandung und Strömung aufgewirbelte und transportierte Sediment fest und bilden zunächst kleine Hügel, die allmählich höher werden, da Lanice die Fähigkeit besitst, bei Übersandungen die Röhre nach oben zu verlängern, so daß über das verschüttete Bäumchen ein neues Röhrenstück mit den typischen Fransenbüscheln aus dem Boden ragt.

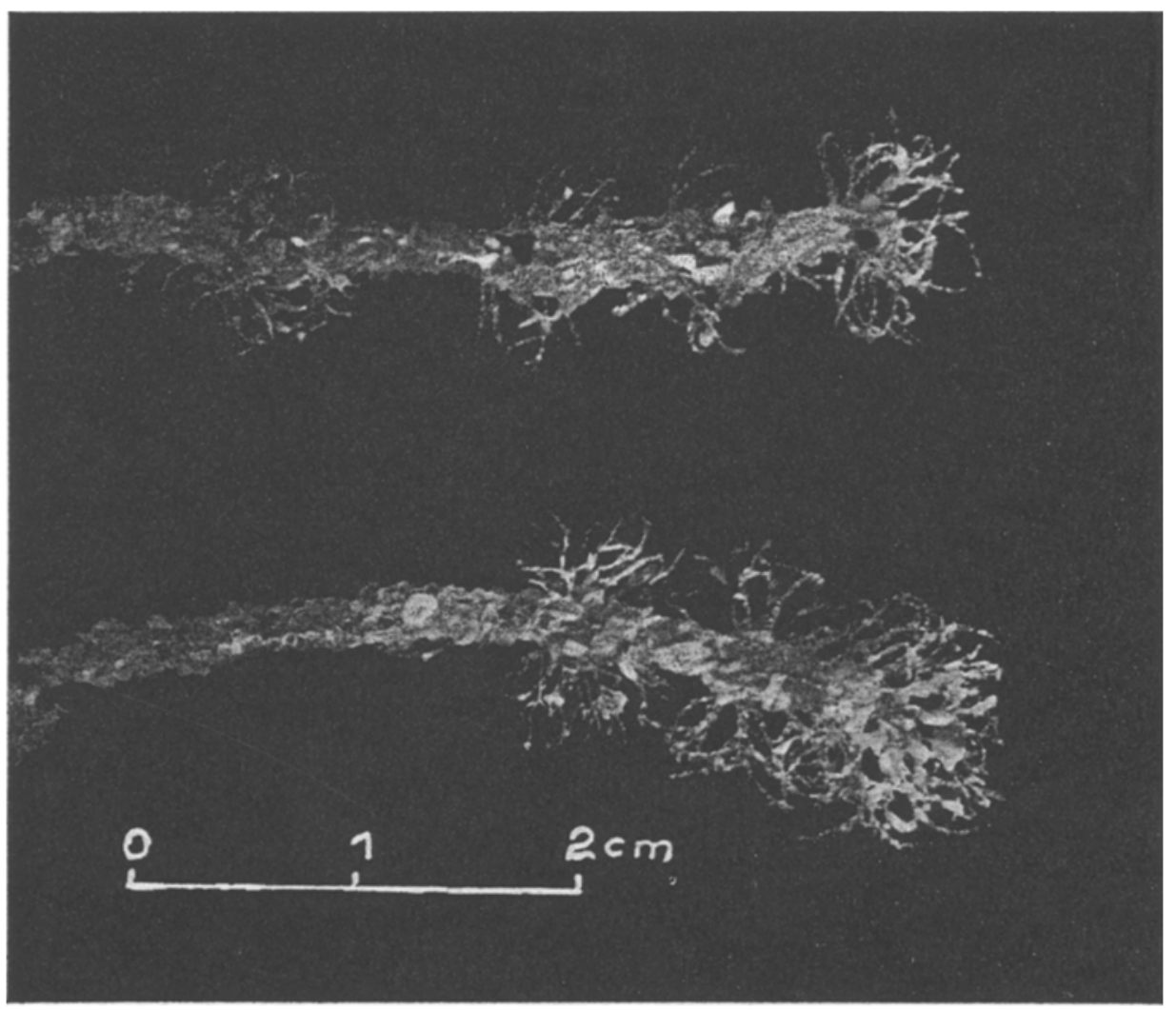

Abb. 4:

Die oberen Enden von Lanice-Wohnröhren mit Stockwerkbildungen aus den Polstersiedlungen des Ellenbogen-Nordstrandes vam Oktober 1950

(Verf. phot.) 


\section{Experimente und Einzelbeobachtungen im Aquarium}

Um diese Art der Erklärung für das Zustandekommen der aufgestockten Lanice-Wohnröhren nachzuprüfen, wurden Experimente durchgeführt, die darüber hinaus einige weitere Feststellungen über die Lebensweise von Lanice und ihr Verhalten beim Wohnröhrenbau ergaben. Für die Versuche wurden in $50 \mathrm{~cm}$ hohe Aquarien (Grundfläche $20 \times 20 \mathrm{~cm}$, s. Abb. 6a) je 2-4 Würmer, die entweder in Röhrenbruchstücken (ohne Bäumchen) saßen, ungefähr senkrecht eingesett (Abb. 6 und 7) oder "nackte“, d. h. aus der Röhre genommene Tiere, auf den Sand gelegt. Meist etwa 12 Stunden nach dem Einbringen ragten die neu gebauten Bäumchen über die Sedimentoberfläche.

\section{Die über die Bodenoberfläche ragenden Röhrenenden und die Stockwerkbildung}

Bleiben die Würmer in den Aquarien ungestört, so schichtet sich nach und nach um das über den Boden ragende Röhrenende ein Kegel auf. Nur im ruhig stehenden Wasser ist diese Kegelbildung möglich; auf den natürlichen Standorten, vor allem in der. Gezeitenzone, wird sie selbstverständlich durch die Wasserbewegungen verhindert. Bei genauer Beobachtung läßt sich das Zustandekommen dieser Aufschüttung um das Lanice-Bäumchen deutlich erkennen. Wie bereits erwähnt, sammelt der Wurm mit seinen Tentakeln das Baumaterial, zum Teil auch Nahrung, von der Bodenoberfläche und befördert das Material zum Prostomium. Dabei sind die Tentakeln nach allen Richtungen ausgespannt und mit den Enden auf dem Boden verankert (Abb. 5a). Andere liegen auf dem Sand und führen schlängelnde Bewegungen aus. Wie auf einem Förderband wandern langsam, aber deutlich sichtbar, kleine Teilchen auf der Cilienrinne der straff gespannten Tentakeln entlang ${ }^{4}$ ). Das dabei häufig noch vor Erreichen der oberen Röhrenöffnung abfallende Bodenmaterial und die beim Einziehen der Tentakeln - wobei die Kontraktion zeitweilig ganz plötglich geschieht - mit an das Bäumchen herangezogenen Sedimentund Detritusteilchen tragen wesentlich zur Bildung des Kegels bei.

An der Entstehung des Kegels ist weiterhin die Kotausscheidung beteiligt, die bei Lanice unter Aquariumsbedingungen in etwa ein- bis eineinhalbstündigen Abständen erfolgt (Abb. 5b). Dadurch wird in unmittelbarer Nähe um das Bäumchen zum größten Teil feinstes Sediment aufgeschichtet. Lanice ist imstande, den Körper in der Röhre so umzubiegen, daß der Wurm das dünnere Hinterende am Prostomium vorbei aus der Röhre strecken kann. Daß die Würmer sich in der Röhre umdrehen können, läßt sich bereits bei den Larvenstadien, die im Plankton der küstennahen Gewässer besonders von Mai bis Juni oft massenhaft zu finden sind, gut beobachten. Die Larve wendet sich häufig in der sie umkleidenden, hyalinen, mehr oder weniger konischen Röhre so um, daß ihr Kopfende (mit den fingerförmigen Tentakeln) nacheinander aus beiden Röhrenöffnungen herausschaut.

Bei den im Sand steckenden Würmern ragt das Hinterende nur etwa eine

4) Gelegentlich der Herstellung eines. Unterrichtsfilms an der Biologischen Anstalt in List auf Sylt im Sommer 1951 wurden von Herrn Dr. Ulrich K. T. Schulz auf unsere Anregungen hin einige Aufnahmen von Lanice-Bäumchen gedreht und die Bewegungen der Sedimentstüdkchen auf den Tentakeln im Laufbild aufgenommen. Der Filmstreifen wurde bei der Tagung der Deutschen Zoologischen Gesellschaft in Wilhelmshaven am 15. 8. 1951 vorgeführt. 


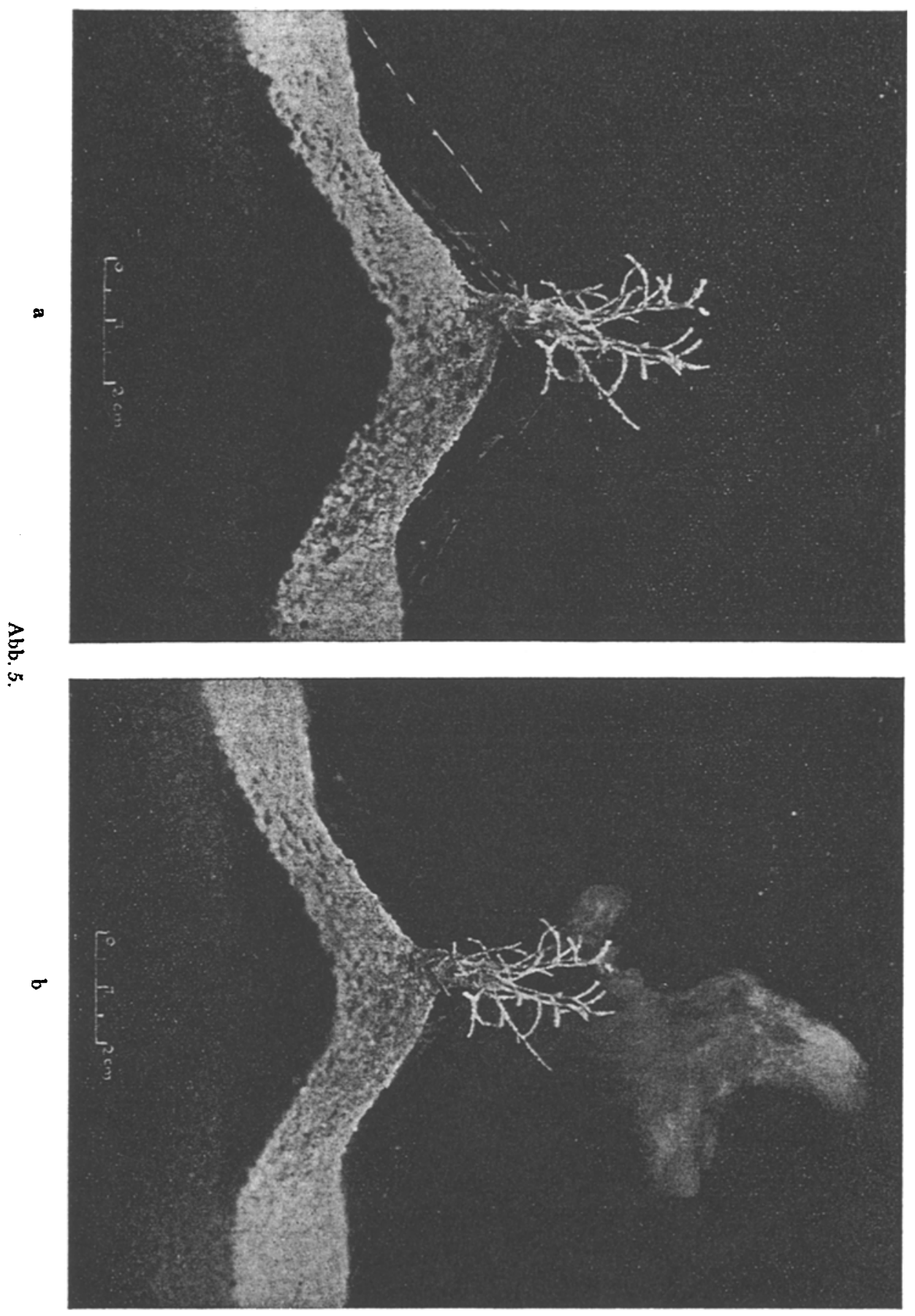

Abb. 5:

Lanice-Bäumchen im Aquarium.

a) Der allmählich aufgeschüttete Kegel zeigt durch seine Nähe an der Glaswand in einem Schnitt feinkörnigeres Material im Vergleich zu dem darunterliegenden Sediment. Ein Teil der Tentakeln sind straff gespannt mit den Enden auf dem Boden verankert und fördern ständig Bodenteilchen (Nahrung und Baumaterial), die bäufig noch vor dem Erreichen der Astchenregion abfallen und so mit zur Kegelbildung beitragen. 
halbe bis eine Sekunde oft bis $20 \mathrm{~mm}$ (etwas geneigt) aus der Ästchenkrone heraus, wobei gleichzeitig eine Kotfontäne ausgestoßen wird (Abb. $5 \mathrm{~b}$ ). Die ausgestreckten Tentakeln werden dabei nicht zurückgezogen. Durch die fortwährende, vom Wurm selbst verursachte Aufschüttung wird das Tier gezwungen, um nicht von den eigenen Kotmassen überdeckt zu werden, sein mit Fransen besetztes Röhrenende ständig höher zu bauen. Beim Hinwegblasen des Kegels mit einer Pipette kommen dann die unregelmäßig am Röhrenschaft stehenden Sandzweige zum Vorschein. Wir finden in diesem Verhalten bereits die Fähigkeit von Lanice angedeutet, eine Übersandung durch Aufstocken der Wohnröhre zu überstehen.

Die Kegelbildung wird also nicht dadurch verursacht, daß, wie KöNrG (1949) angibt, nach dem Einsetzen der Würmer aus der Röhre Sandkörnchen „im Laufe der nächsten Stunden und Tage fast ununterbrochen einzeln oder in größerer Menge mit geringer Geschwindigkeit herausfliegen", sondern das Material wird durch die Tätigkeit der Tentakeln und die Kotausscheidung am Bäumchen kegelförmig aufgeschichtet und stammt ausschließlich von der Bodenoberfläche.

Deutlicher ist die Stockwerkbildung zu erkennen, wenn die im Aquarium eingesetzten Würmer in beliebig langen Zeitabständen mit Sedimenten verschiedener Korngröße überdeckt werden. Die Anfärbung des Sandes für einzelne Schichten mit Sudanrot erwies sich dabei als sehr vorteilhaft. Die Dicke der geschütteten Sandschichten betrug bei den Versuchen $5-7 \mathrm{~cm}$. Nach jeder Ubersandung hatten die Würmer stets in der einer Sandschüttung folgenden Nacht ihre bis über die neue Bodenoberfläche ragenden Bäumchen fertiggestellt (Abb. 6 und 7). Daß Lichteinwirkungen die Bautätigkeit im Boden nicht beeinflussen, ist, wie auch SeILACHer anführt, leicht einzusehen. Das Bäumchen über der Bodenoberfläche aber baut der Wurm nur bei Dunkelheit, was nach jeder der zahlreichen Ubersandungen während der Versuche im Aquarium beobachtet werden konnte, worauf auch WATSON (1890) bereits hinwies.

Die Form der Lanice-Bäumchen und deren Höhe über dem Boden sind, wie die folgenden Aquariumsbeobachtungen zeigen, von bestimmten Umweltbedingungen abhängig. Darüber hinaus bestätigen sie eindeutig die Annahme Watsons, nach der die Fransenbüschel vor allem beim Nahrungserwerb für die Würmer von Bedeutung sind.

Mit dem Ansteigen der Wassertemperaturen kam es im Frühjahr in den Aquarien zu einer Massenentwicklung von Schlauchdiatomeen, die den Sandboden und die Glaswände der Becken dicht überwucherten und auch die Sandzweige der Lanice-Bäumchen stark verfilzten. Die Aktivität der Würmer, bei denen vordem häufig lebhafte Tentakeltätigkeit und Kotausscheidungen beobachtet werden konnten, ließ allmählich nach und es hatte den Anschein, als ob die Tiere abgestorben wären. Nach kurzer Zeit jedoch bauten die Würmer

b) Dasselbe Tier, eine Kotfontäne ausstoßend. Die Aufnahme zeigt durch die Wahl der Belichtung von 1 Sekunde den Vorgang gerafft und die gesamte Kotmenge, die aus feinkörnigem, zum Teil flockigem, etwas länger im Wasser schwebendem Material und kleinen Sandkörnchen besteht, die schneller absinken, wie die aus der Kotwolke nach unten ziehenden Streifen erkennen lassen. Bei der Kotausscheidung bleiben die Tentakeln ausgestreckt, von denen ein Teil den Boden abweidet, während andere in den Fransen entlangstreichen und von den Spitzen der Ästchen aus Bewegungen im freien Wasser ausführen.

Deutlich ist in den Abbildungen 5a) und b) die Anordnung der Fransen in zwei, mit ihren Ebenen parallel zur Blickrichtung liegenden Lappen zu erkennen. (Verf. phot.) 
über die verfilzten Bäumchen etwa 5-8 mm lange Röhrenstücke, auf die sie einen neuen Kranz von Fransen setzten. Diese Feststellung scheint auch der Beobachtung Ehlers' (1875), der sie aber nicht deutete, zugrunde zu liegen, nach der "gelegentlich auch einmal ein Wurm eine zylindrische Röhre wieder über die mit Anhängen beseţte Mündung hinausbaut". Wir können das Verhalten der Würmer nur so erklären, daß ihnen die verklebten und verfilzten Fransen ein Absammeln von Nahrungsteilen erschweren.

Weitere Beobachtungen lassen einen Zusammenhang zwischen der Höhe der Bäumchen und den Ernährungsbedingungen erkennen: Nur $1-2 \mathrm{~mm}$ hohe Bäumchen über der Bodenoberfläche bauten die Würmer nach den Sandüberschüttungen, nachdem die Wände der Aquarien von dem Belag vollkommen gesäubert wurden. Dieser Bewuchs enthielt neben den Schlauchdiatomeen auch andere, für die Ernährung wichtige Diatomeenarten und Kleintiere und wurde vor allem von den in der Nähe der Glaswände im Boden sitzenden Tieren abgeweidet. Hierbei war besonders gut die Verwendung der Fransen als Angelruten zu erkennen. Das zu den Übersandungen benutgte Sediment ist für diesen Zweck gut gereinigt und so vorbehandelt worden, daß es kaum Nahrung (Mikro- und Meiobenthos) für die Würmer enthalten konnte, und ferner wurde ein neuer Bewuchs an den Beckenwänden verhindert. Bei geringerer Nahrung ist Lanice gezwungen, die Ästchen dem Boden näher zu bauen, um die nahrungsärmere Bodentrübe mit dem ."Stellnet" ergiebiger erfassen und die Bodenoberfläche besser abweiden zu können. Dabei sind die radial nach allen Richtungen um das Bäumchen ausgehenden Weidespuren auf dem Sand der Aquarien zu erkennen, und besonders eindrudksvoll ist das strahlenförmige Abbild der Tentakeltätigkeit, wenn die frischgeschüttete Sandschicht mit einer ganz dünnen Lage gefärbten Sediments bedeckt wird. Bei reichlicher Nahrung ist die Bauweise einer dicht am Boden sigenden Fransenkrone nicht notwendig, ja sie kann sogar zu einer Verfilzung der Bäumchen führen, wie sich bei der oben beschriebenen Beobachtung zeigte.

\section{Das Bauen im Sediment}

Weitere Beobachtungen erlauben ein Urteil über die Bauweise und die Form der Lanice-Röhren im Boden. Nach der Mitteilung von KöNIG (1949) baut Lanice im Inneren des Sediments mit Hilfe der Tentakeln und eines Wasserstrudels, durch den „die Sandmasse oberflächlich gelockert wird. Das losgelöste Material befördert der Wurm an seinem Körper vorbei und zur Röhrenöffnung heraus“. SeILACHer (1951) vergleicht die Bauweise im Sediment mit dem Prinzip eines "modernen Druckspülbohrers". Nach der Darstellung von KöNIG müßte das zum Bau nicht verwandte Material, das in seiner Gesamtheit etwa dem Volumen des Röhrenhohlraumes entspräche, auf der Oberfläche des Bodens zu beobachten sein. Daß dies aber nicht der Fall ist, läßt sich an Hand der Abb. 6, in der das Ergebnis eines auf Seite 117 besprochenen Aquariumsversuches dargestellt ist, gut demonstrieren. Berechnen wir den Inhalt des Röhrenhohlraumes der U-Röhre von der Buccinumschale $a b$, so ergeben sich bei einer durchschnittlichen Weite des Röhreninneren von $4,5 \mathrm{~mm}$ und einer Länge von $650 \mathrm{~mm}=10340 \mathrm{~mm}^{3}$. Diese Sedimentmasse müßte also vom $W$ urm nach außen befördert werden und zu einem Kegel mit einem Grundflächendurchmesser von $36,2 \mathrm{~mm}$ und einer Höhe von $30 \mathrm{~mm}$ aufgeschüttet sein, der, wie ein in Abb. 6b eingezeichneter Schnitt verdeutlicht, das Bäumchen des zuerst gebauten Schenkels fast völlig verdecken würde. Wie die 
Abb. 6a aber zeigt, ist um das Bäumchen nur eine schwächere Kegelbildung zu erkennen, die durch die Tentakeltätigkeit und die Kotausscheidung verursacht wird (vgl. S. 115).

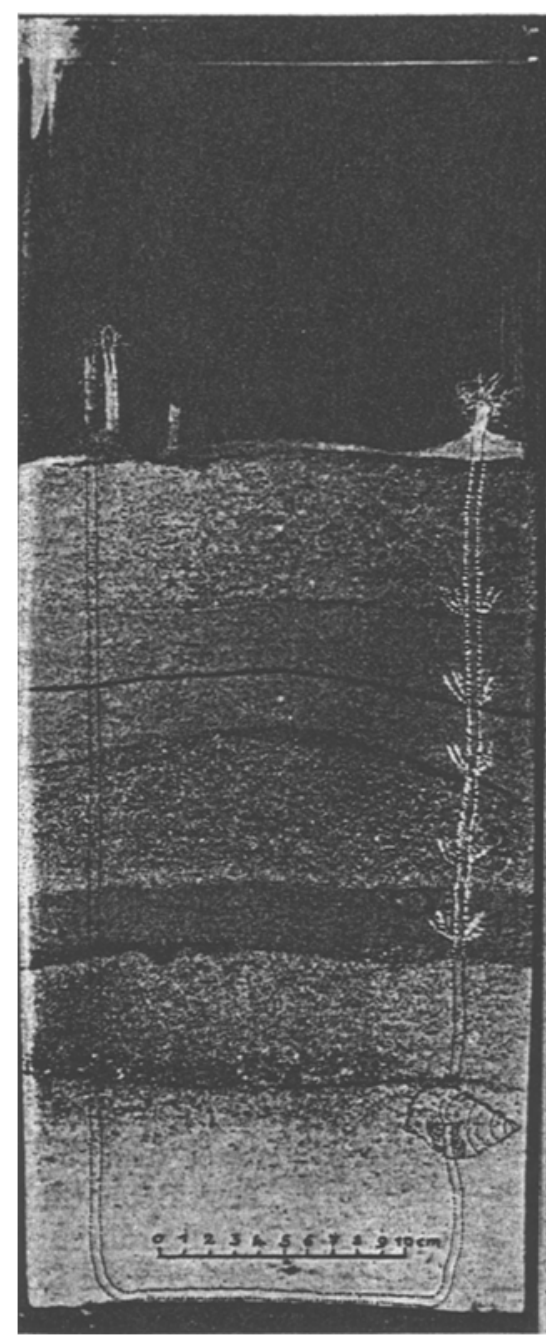

a

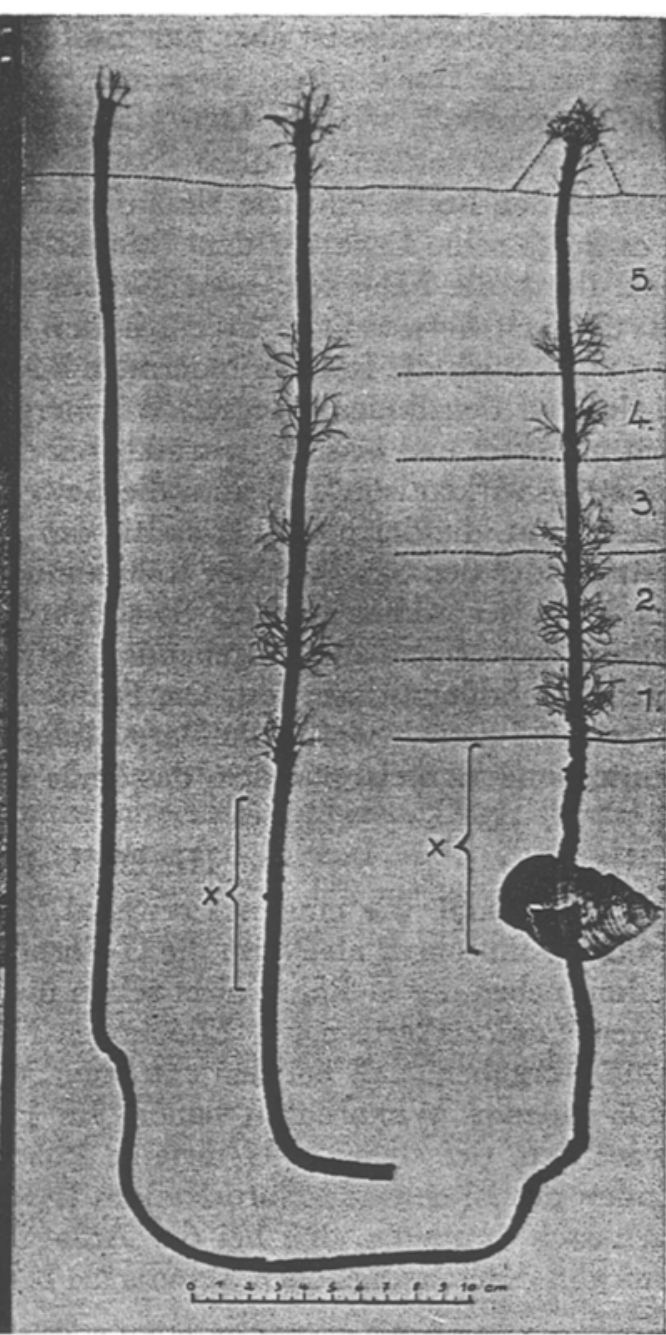

Abb. 6:

b

a) Totalansicht eines der für die Versuche benutzten Aquarien mit zwei eingesetzten $W$ ürmern nach 5 Obersandungen. Punktiert eingezeichnet ist die Lage einer nach dem Ausspülen in

b) abgebildeten vollständigen U-Röhre mit Stockwerkbildungen der Bäumchen an einem Schenkel. Von der zweiten Röhre ist nur eine Seite dargestellt. Beide Würmer wurden in Röhrenstücken $(X)$ fast senkrecht eingesetzt, von denen eine Röhre mit ihrem unteren Ende in einer mit Sand gefüllten Buccinum-Schale saß. Der über der linken oberen Röhrenöffnung eingezeichnete Kegel gibt die Gesamtmenge an, die von dem Wurm beim Bauen im Sediment aufgeschüttet worden wäre, wenn die Annahme von KöNIG (1949) zutreffen würde.

(Verf. phot.)

Einen Hinweis auf die Bauweise im Sediment geben uns Beobachtungen an Würmern, die "nackt" (ohne Röhren) auf die Oberfläche einer etwa 5-6 cm dicken Sandschicht in eine Glasschale gelegt werden, wobei das Verhalten der Tiere gut unter dem Binokular verfolgt werden kann. Die Würmer umgeben 
sich bald nach dem Auflegen auf die Bodenoberfläche mit einer ,provisorischen" Sandhülle (vgl. KöNIG 1949 und SEIzACHER), die dadurch entsteht, daß auf dem von den Drüsenpaaren der Bauchschilder ausgeschiedenen Schleimmantel (Grundschicht der Röhre) Sedimentteilchen festkleben. Dieses zuerst angelegte Röhrenstück ist aber nur insofern "provisorisch“, als es einen ersten Schut für das Tier darstellt. In seiner Struktur und Festigkeit aber gleicht es dem Röhrenschaft, wie ihn Lanice auch innerhalb des Bodens herstellt.

Schon bei der Anlage dieser Schutgröhre dringt der Wurm mit dem Kopf voran in den Boden ein. Die Hauptfunktion übt hierbei das Prostomium aus, da es durch seine Lage vor den Tentakeln und Kiemen (vgl. Abb. 1) und vor allem durch die Fähigkeit, seine Gestalt zu verändern (Abb. 2), die für eine Bohrtätigkeit notwendigen Eigenschaften besitgt. Beim Durchdringen des Bodens wird durch die formverändernden Bewegungen des Prostomiums, die auch bei den auf den Boden gelegten Würmern gut zu beobachten sind, das Sediment gelockert und beiseite gedrückt. Bei der Lockerung des Sediments an der Bohrstelle wirken zum Teil auch die Bewegungen des in der Röhre stehenden Wassers mit, die durch die Peristaltik des Wurms entstehen. Von einem Wasserstrom, der den Sand vor der Röhrenmündung im Boden hinwegspült. kann aber kaum gesprochen werden. So schiebt sich das Tier langsam in der Bohrrichtung weiter und die umgebenden Sedimentteilchen kitten auf der ausgeschiedenen Schleimschicht fest. Die Fransen werden niemals im Boden auf den Röhrenrand gesetzt, wofür die Darstellung von KöNIG (1949, S. 405) sprechen könnte, sondern stets, nachdem das Ende der Röhre ins freie Wasser ragt.

\section{Die U-Röhre}

KöNIG fand, wie eingangs erwähnt, „nach zahlreichen Aufgrabungen bei Lanice-Wohnröhren als Norm die U-Form" und SEILACHER stellte im Watt bei Mellum neben der U-Röhre nicht selten die W-Form fest. Häufige Grabungen in den Lanice-Polstern am Ellenbogen-Nordstrand im Herbst und Winter 1950/51 ergaben, daß bei der extremen Wohndichte die Würmer im Boden blind endende Wohnröhren bauen. Im Herbst 1951 konnten vereinzelt bis etwa $15 \mathrm{~cm}$ tief stehende U-förmige Röhren in einigen weniger dichten $\mathrm{Be}$ ständen des Ellenbogen-Nordstrandes freigelegt werden ${ }^{5}$ ). Diese Beobachtungen lassen vermuten, daß bei der Anlage von U-förmigen Wohnröhren bei Lanice in den verschiedenen Standorten bestimmte Umweltfaktoren eine Rolle spielen.

Das Bauen von U-Röhren in den Lanice-Polstern wird den Würmern besonders dadurch erschwert, daß in den extrem dichten Beständen, bei denen, wie die Abb. 3b zeigt, eine Röhre neben der anderen steht, kaum der Plaţ für den zweiten Schenkel vorhanden ist. Weiterhin müßten die Tiere bei der Anlage des unteren, mehr oder weniger waagerecht liegenden Teiles der U-Röhre, durch die dicht stehenden senkrechten Röhren behindert, immer tiefer bauen. Bei einer derartigen Bauweise würde sich eine Verschiebung des Horizontes der unteren Röhrenteile nach der Tiefe ergeben, was aber niemals beobachtet werden konnte. Andererseits liegt, abgesehen von dem Raummangel bei der

5) Die bei den Grabungen sorgfältig durchgeführte und auch leicht anzuwendende Methode, bei der die bis etwa $10 \mathrm{~cm}$ tiefer als der Horizont der unteren Röhrenenden reichenden Ausstiche so im Wasser ausgespült wurden, daß das Freilegen sämtlicher Wohnröhren mühelos möglich war, entkräften den Einwand (bei KöNIG 1949, Seite 405), nach dem im Gewirr von Röhren deren Lage und Form nicht einwandfrei festzustellen sind. 
sehr dichten Besiedelung, aber auch die Notwendigkeit des Bauprinzips der U-Form für Lanice nach Bau und Funktionen des Wurmkörpers nach folgenden Überlegungen nicht vor:

1. Durch die oben besprochene Art des Nahrungserwerbs erübrigt. sich der am gesamten Körper vorbeistreichende Nahrungsstrom und damit die U-Form der Wohnröhre.

2. Nach der Art der Kotausscheidung (s. S. 115 und Abb. 5b) ist eine U-förmige Röhre, etwa wie bei Arenicola (Kopf- und Kotgang) nicht erforderlich.

3. Auch in atmungsphysiologischer Hinsicht braucht Lanice keine U-Röhre, da die unmittelbar hinter dem Buccalsegment stehenden, reich verzweigten Kiemen (Abb. 1b) dem Wurm die Atmung im Bereich des meist bewegten Wassers in der Ästchenregion ermöglichen. Stellen wir Lanice Arenicola gegenüber, bei der 13 Paar Kiemen an den Segmenten der Körpermitte stehen und so einen am Körper entlanglaufenden Atemwasserstrom und damit einen U-förmigen Wohngang notwendig machen, so erhalten wir die Parallele zu einem Vergleich, den LiNKe (1939) zwischen Pygospio und Polydora zieht. Pygospio besitgt außer den an den Parapodien sitenden kleinen Kiemen die dicken Tentakeln am Vorderende, die auch im Dienste der Atmung stehen. Pygospio braucht deshalb keinen U-Bau mit ständigen Wasserdurchfluß; während Polydora mit größeren Körperkiemen einen U-förmigen Wohnbau besitgt.

4. Schließlich kann das Fehlen von Mitbewohnern in Lanice-Wohnröhren ${ }^{6}$ ) die angeführten Punkte, die gegen die Notwendigkeit der Bauweise vor U-förmigen Wohnröhren bei Lanice sprechen, ergänzen. Obgleich die gegenseitigen Beziehungen dieses Zusammenlebens noch nicht geklärt sind, darf aber die Vermutung ausgesprochen werden, daß nur der durch einen U-Bau bedingte Wasserstrom diesen „Untermietern" die primären Lebensbedingungen schafft.

Das Experiment und die Beobachtungen am natürlichen Standort lassen erkennen, daß bei der Anlage einer U-Röhre besondere Umstände eine Rolle spielen, von denen die Ernährungsbedingungen an erster Stelle zu stehen scheinen. Diese Feststellung würde sich auch mit der Beobachtung decken, nach der in den extrem dichten, mit Nahrung reichlich versorgten Lanice-Polstern nur ganz selten U-Röhren gefunden wurden. Herr Dr. KöNIG konnte (nach einer freundlichen Mitteilung) an den Stellen "die U-Röhren klar freilegen", an denen "keine maximal dichte Besiedelung, also wahrscheinlich keine optimalen Lebensbedingungen" anzutreffen waren. Bei dem in Abb. 6b dargestellten Ergebnis eines Versuches schien für das Zustandekommen der U-Röhre außer den Ernährungsbedingungen noch ein weiterer Faktor verantwortlich gewesen zu sein, und zwar der Chemismus der Oberfläche und des Wassers. Das Bauen von U-Röhren wurde zu einer Zeit beobachtet, als nach dem Aussetzen der Frischwasserzufuhr das Aquarium vollkommen ruhig stand. Daß die Würmer trotz konstanter, durch das Ausbleiben der im Zulaufwasser mitgeführten Nahrung zum Teil noch ungünstiger gewordenen Lebensbedingungen die Bäumchen aufstockten, deutet auf das Bestreben hin, aus der unmittelbar über dem Boden durch die Zersetzung entstandenen sauerstoffarmen, unteren Wasserschicht berauszukommen. Einige Tage nach dem Aufstocken der Bäum-

B) Im Gegensatz zu Lanice ist in den U-Röhren von Amphitrite Johnstoni fast regelmäßig Gattyana cirrosa anzutreffen, und nach KöNIG (1943) fanden sich in Arcnicola-Gängen Lepidonotus squamatus und Eunoe nodosa; vgl. ferner EALES (1950). 
chen ragten zwei neue Röhrenenden über die Sandoberfläche, die sich beim Ausspülen des Aquariums als zweite Schenkel von U-förmigen Wohnröhren nachweisen ließen. (Dauer des Versuches $=34$ Tage.)

Ein Beispiel aus einem für Lanice ernährungsmäßig ungünstigen Standort zeigt die Abb. 8. Die U-Röhre mit dem darin sitzenden Wurm wurde am 6. 9. 1951 aus einer Probe mit dem vaN VeEN-Bodengreifer bei der Station "Nordhafen innen" (etwa $5 \mathrm{Sm}$ nordwestlich von Helgoland - $34 \mathrm{~m}$ Tiefe sandiger Schlick - Greifertiefe ca. $13 \mathrm{~cm}$ ) herauspräpariert.

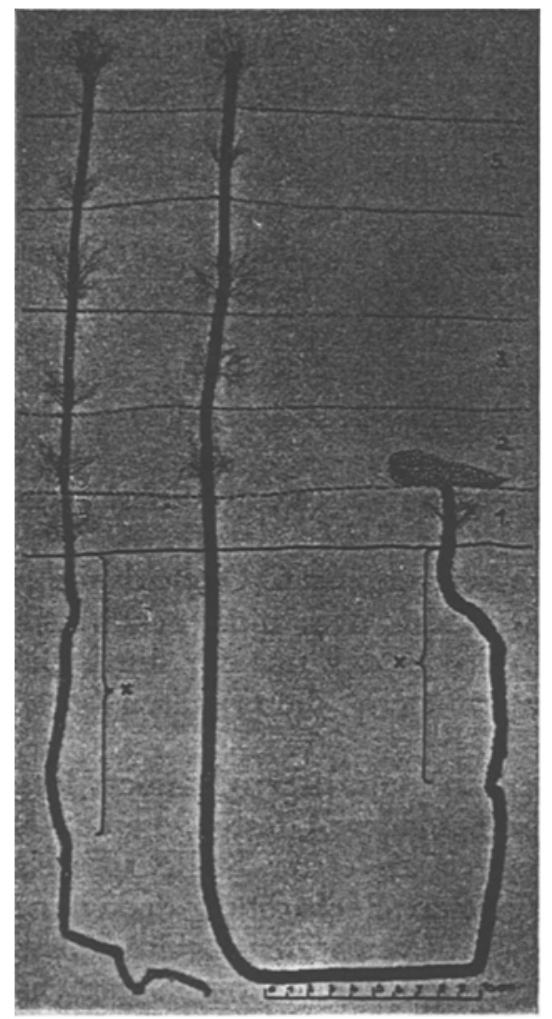

Abb. 7.

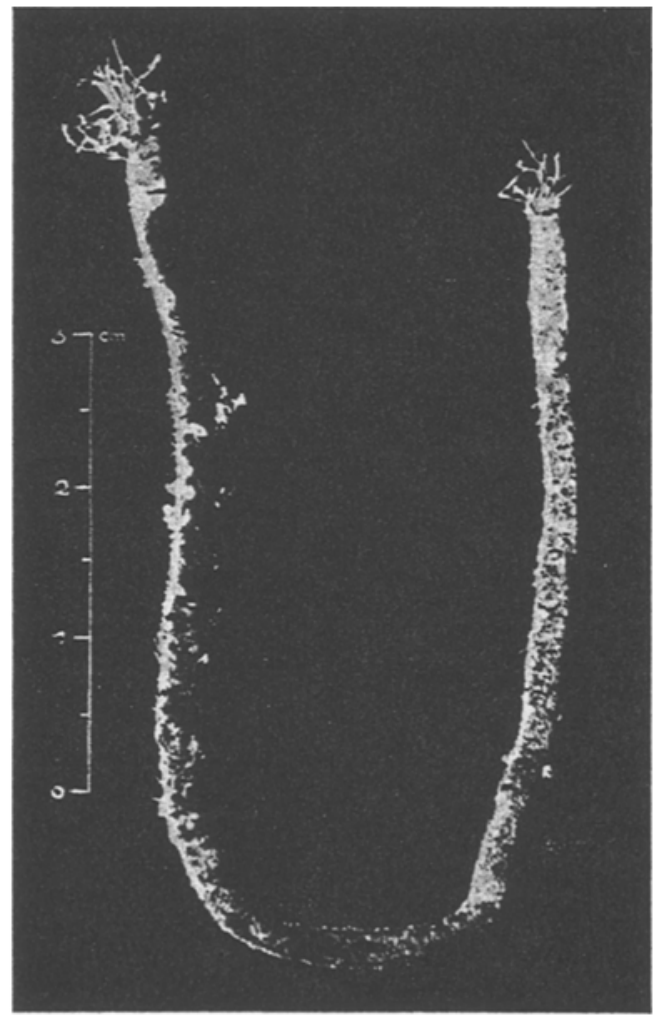

Abb. 8.

Abb. 7: Die ausgespülten Wohnröhren eines Versuches, bei dem nach der ersten Ubersandung auf die Stelle der oberen Offnung einer Röhre ein Ziegelsteinstückchen gelegt wurde (punktiert eingezeichnet). Nach dem Entfernen des Steines und den folgenden Sandüberschüttungen wurde nur ein Schenkel weitergebaut, während der andere, trotz der von SeILAcher angenommenen notwendigen „Bewetterung“, unberücksichtigt blieb. Der als Kontrolle mit eingesetzte Wurm baute nur eine senkrechte, unten Blind-endende Wohnröhre.

$X=$ Länge der bei Beginn des Versuches eingesetzten Röhrenstüdke. (Verf. phot.)

Abb. 8: U-förmige Lanice-Wohnröhre aus dem Bodengreifer herauspräpariert (nordwestlich Helgoland - sandiger Schlick - $34 \mathrm{~m}$ Tiefe).

(Verf. phot.)

Wie die folgende Aufzählung des Bodentierbestandes verdeutlicht, ergaben sich für die seßhaftere Lanice durch die eingetretene Nahrungskonkurrenz infolge der zum Teil dichten Besiedelung von anderen, weniger sessilen Bodentieren schlechtere Lebensbedingungen, die den Bau einer U-förmigen Röhre verursachten. 
Die $1 / 10$ qm Bodengreiferprobe enthielt: zahlreich Phoronis Mülleri; 2 Phyllodoce grönlandica; 10 Nephthys hombergi; 4 Goniada maculata; 2 Owenia fusiformis; einige Myriochele heeri; 2 Pectinaria koreni; 1 Pectinaria auricoma; 2 Lanice conchilega; 8 Diastylis rathkei (Cumacea); 11 Ampelisca brevicornis (Amphipoda); 1 Processa canaliculata (Decapoda Natantia); 2 Nymphon rubrum (Pantopoda); 4 Lunatia nitida; 68 Nucula nitida; 5 Montacuta ferruginosa; 4 Venus gallina; 10 Abra nitida; 1 Phaxas pellucides; 135 Aloidis gibba; 16 Ophiura albida; 5 Echinocardium cordatum.

Ein weiterer Umstand, der Lanice in diesem Standort zum Bau einer U-Röhre veranlaßt zu haben scheint, ist das Verhalten der in Flecken dichter Besiedelung vorkommenden Korbmuscheln Aloidis gibba, die mit ihren Byssusfäden die auf und unmittelbar unter der Oberfläche liegenden und sitzenden Tiere, Pflanzen und deren Reste zu einem festen Gespinst verfilzen (vgl. ZiEGELMEIER, 1951).

Den wohl sichersten Beweis, daß Lanice: eine U-Röhre nicht braucht, lieferte ein Versuch, bei dem zwei Würmer in ein Aguarium eingesett wurden. Nachdem beide Würmer ihre Bäumchen fertiggestellt hatten, wurde sofort nach Einbringen der ersten Sandschicht ein Tier mitjeinem Ziegelsteinstückchen bedeckt, so daß ein Weiterbauen der Wohnröhre an dieser Stelle unmöglich war ${ }^{7}$ ). Bereits nach 28 Stunden konnte in etwa $12-13 \mathrm{~cm}$ Entfernung die obere Offnung des zweiten Röhrenendes auf der Sedimentoberfläche des Aquariums beobachtet werden. Nach zwei Tagen wurde das Steinstückchen wieder entfernt und das Aquarium weitere 24 Stunden in dem Zustand belassen. An der Stelle der ersten oberen Röhrenöffnung war nur ein kleines Loch zu erkennen, ohne daß eine Fransenkrone gebaut worden war. Bei den darauf folgenden vier Überschüttungen mit Sand verschiedener Korngröße in den einzelnen Schichten wurde nur ein Schenkel hochgebaut, während der andere unberücksichtigt blieb (Abb. 7). Auch das Abschneiden des' nach der fünften Übersandung gebauten Bäumchens veranlaßte den Wurm nicht, die angelegte U-Röhre zu vervollständigen. Nach etwa 24 Stunden war das entfernte Bäumchen durch ein neues ersett. Der als Kontrolle eingesetzte zweite Wurm baute eine einfache, senkrecht nach unten gehende Wohnröhre, die einige Zentimeter am Boden des Aquariums entlanglief und blind endete (Versuchsdauer $=31$ Tage).

\section{Beobachtungen am natürlichen Standort}

\section{Vorkommen von Lanice}

Das Wohngebiet von Lanice conchilega beschränkt sich nicht nur auf die Gezeitenzone, sondern die Würmer kommen, oft in Flecken reicherer Besiedelung, in rein- bis schlidksandigen Standorten bis zu Tiefen von über $30 \mathrm{~m}$ vor. Erwähnt sei in diesem Zusammenhang, daß Lanice besonders von den Schollen zuweilen in solchen Mengen gefressen wird, daß mitunter Magen und Darm mit den meist noch in ihren Röhren steckenden Tieren prall gefüllt sind. HAGMEIER (1930) fand bei Untersuchungen im Bonitierungsgebiet vor Norderney-Borkum in einem "Fleck“ von Spisula subtruncata am 7. 9. 1928 in

7) Daß ähnliche Verhältnisse auf dem natürlichen Standort eintreten können, wenn durch das ständig bewegte Wasser in der Gezeitenzone ein Stein, eine Muschel- oder Schneckenschale über ein Lanice-Bäumchen zu liegen kommt, ist leicht einzusehen. 
einer ${ }^{10} \mathrm{qm}$ Bodengreiferprobe (Tiefe $=17 \mathrm{~m}-$ blauschwarzer Sand mit Schlick; Oberschicht braungrau, Unterschicht $\mathrm{H}_{2} \mathrm{~S}$-Geruch - Probentiefe etwa $8 \mathrm{~cm}$ ) 21 Lanice conchilega in Wohnröhren (vgl. HagmeIer, 1951, Tafel XIX, S. 220). Caspers (1939 und 1950) wies Lanice für die Helgoländer Tiefe Rinne und die Helgoländer Austernbank aus Tiefen von $30-50 \mathrm{~m}$ auf meist schlicksandigem Untergrund nach, allerdings "nicht häufig, meist nur ein Tier in einem Fang".

Nach einer Zusammenstellung der Polychaeten-Fundorte um Island von Elise Wesenberg-Lund wurde Lanice conchilega, die an einigen Stellen in den Gewässern vor der Süd- und Südwestküste Islands vorkommt, bis zu Tiefen von $326 \mathrm{~m}$ nachgewiesen.

Nach den seit Oktober 1949 wieder aufgenommenen Bodengreiferuntersuchungen im Ostteil der Deutschen Bucht ist Lanice conchilega fast im gesamten Gebiet anzutreffen und besiedelt vor allem die küstennahen, sandigen Gründe von Graa-Dyb (Esbjerg-England-Weg) bis südlich in Höhe der Hever-Mündung. Die Anzahl der mit dem ${ }^{1 / 10}$ qm VAN VEEN-Bodengreifer heraufgebrachten lebenden Würmer ist auch in diesem Gebiet verhältnismäßig gering (im Maximum 7 Tiere), obgleich die im Siebrest oft zahlreich auftretenden leeren Wohnröhren, von denen, ihrem Aussehen nach, angenommen werden muß, daß sie bis zum Zeitpunkt der Probeentnahme bewohnt waren, eine viel dichtere Besiedelung mit Lanice vermuten lassen. Die Erklärung hierfür liegt in dem Verhalten der Würmer, bei der geringsten Erschütterung sich weit in das Röhreninnere zurückzuziehen, wie auch Aquariumversuche zeigen. Das Aufsetzen des Greifers auf die Bodenoberfläche und die dabei über dem Boden entstehenden Wasserbewegungen bewirken das Zurückziehen der Tiere, so daß von den unteren, scharfen Kanten der Greiferschalen bei den im Sand maximalen Probentiefen von etwa $8 \mathrm{~cm}$ nur das obere, leere Ende der Röhre abgeschnitten wird.

Der unmittelbaren Beobachtung zugänglich sind die Lanice-Bestände bei Tiden-Trodkenzeit in den Standorten der Gezeitenzone. WoHLenberg fand Lanice im Königshafen/Sylt "sehr häufig - bis zu 1500 Stück auf 1 qm innerhalb der Zostera marina-Wiese an der Niedrigwassergrenze" und LiNke (1939) konnte beobachten, daß im sonst Lanice-armen, schlickigen Jadebusenwatt , an den Spitzen mancher Sandbänke", auf denen „es häufig zu starker Anreicherung von Bruchschill kommt", Lanice-obwohl spärlich - anzutreffen ist. Die Angaben von WoHLEnBerg und Linke über das Vorkommen von Lanice im Watt deuten bereits auf eine Tatsache hin, die sich durch Beobachtungen im Königshafen-Watt und am Ellenbogen-Nordstrand bestätigen ließ, daß bei Lanice drei Faktoren für die Besiedelung bestimmter Standorte entscheidend sind: 1. Die Zusammensetzung und Korngrößen des Sediments, 2. die Ernährungsbedingungen und 3. die Lage der Standorte in bezug auf Wassertiefe und -strömungen und das Verhältnis der Trockenliege- und Wasserbedeckungsszeit der Böden in der Gezeitenzone.

Im Königshafen siedelt Lanice einzeln oder in kleinen und großen Flecken, die oft zu dichteren Rasenbildungen führen können. Häufig sind derartige Flecken unter den Fucus mytili-Büscheln der Miesmuschelbänke zu beobachten, wobei den Würmern während der Zeit des Niedrigwassers zugleich ein natürlicher Verdunstungsschut gegeben wird. Bemerkenswert ist die Feststellung, daß dichte Bestände von Lanice-Bäumchen besonders im grobkörnigen Wattboden gefunden werden. Während das feinsandige Arenicola- 

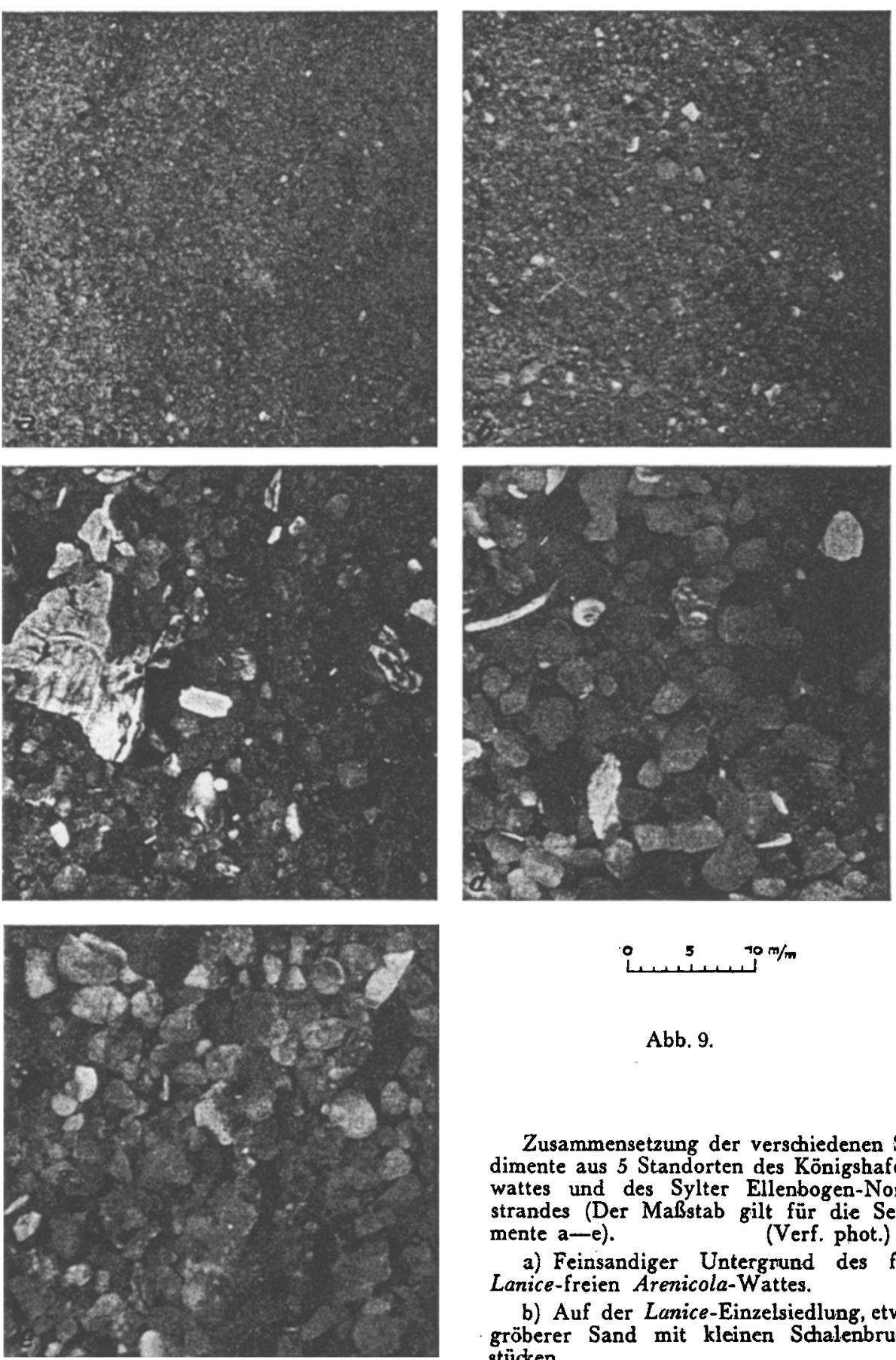

Abb. 9.

c) Der zum Teil grobe, mit größerem Bruchschill durchsetzte Untergrund eines LaniceFleckens unter einem Fucus-mytili-Büschel.

d) Die Bodenbeschaffenheit eines Lanice-Rasens, grober Sand und Bruchschill. ( $a-d=$ Königshafen-Watt/Sylt).

e) Aus einem Lanice-Polster am Sylter Ellenbogen-Nordstrand, fast kiesiger Sand mit Bruchschill. Die Zusammensetzung des Sediments entspricht der von d). Der Standort zeigt aber wegen der besonders günstigen Ernährungsbedingungen eine viel dichtere Besiedelung. 
Watt fast frei von Lanice ist, nehmen die Bestandszahlen mit steigender durchschnittlicher Korngröße zu, wie die Zusammenstellung einzelner Sedimente in Abb. 9 zeigt.

Es ist anzunehmen - weitere Untersuchungen sollen diese Vermutung noch bestätigen - daß der rauhe, grobkörnige Untergrund den bodenreifen Larvenstadien die günstigen Ansaţbedingungen schafft, wie auch WILSON (1948) für die bodenreifen Larvenstadien von Ophelia bicornis eine Abhängigkeit vom Sediment bei der Wahl des Untergrundes nachweisen konnte. Daraus würde sich auch ergeben, daß Lanice den reinen Schlick kaum besiedeln wird, wobei noch zu erwähnen ist, daß den Würmern in diesem Sediment zur Herstellung der Wohnröhre das Baumaterial fehlt. Treten zu den geeigneten Ansaţbedingungen des Untergrundes dann noch günstige Ernährungsverhältnisse hinzu, so kommt es zu den erwähnten extrem dichten Lanice-Siedlungen, wie sie am Nordstrand des Ellenbogens beobachtet werden können.

\section{Riffartige Lanice-Polster am Sylter Ellenbogen-Nordstrand}

Die riffartigen, dichten Lanice-Polster am Nordstrand des Ellenbogens sind nach Beobachtungen im Oktober 1950 und im Frühjahr 1951, als bei heftigen Ostwinden das Wasser stark ablief und die Siedlungen trocken fielen, zwischen den der Ostspitge des Ellenbogens am nächsten liegenden Buhnen besonders ausgeprägt. Für die Schaffung der günstigen Voraussetgungen für die Entwicklung derart dichter Bestände gerade an diesen Stellen spielen wahrscheinlich die folgenden Gegebenheiten die wichtigste Rolle:

1. Der für den Ansats der bodenreifen Larvenstadien geeignete, grobkörnige und bruchschillreiche Untergrund.

2. Die fast ständige Wasserbedeckung garantiert eher die Weiterentwicklung der sich ansetzenden Larvenstadien, als das auf den Wattböden, die regelmäßig einige Stunden trocken liegen, der Fall ist.

3. Den Würmern werden auf diesem Standort sehr gute Ernährungsbedingungen dadurch geschaffen, daß hier von dem abfließenden Wasser, das mit verhältnismäßig hoher Geschwindigkeit um die Ostspitze des Ellenbogens herumfließt, die aus dem Königshafenwatt mitgeführte, mit Nahrung angereicherte Wassertrübe durch Wirbelbildung zwischen den am weitesten nach Osten liegenden Buhnen in größerem Maße zum Abseten gelangt.

4. Werden auf dieselbe Weise, wie die durch die besonderen Strömungsverhältnisse angereicherte Nahrung auch viele bodenreife Larven in diesem Gebiet zu Schwärmen oder Wolken angehäuft.

Dicht an dicht, wie die Haare einer Bürste, stehen in diesem Biotop die Lanice-Wohnröhren bis 1000 Stück auf $1 / 10$ qm (Abb. 3b) und festigen so diese Strandteile und schützen sie gegen weitere Abtragung durch das Wasser. Wie stark mitunter die Wirkung der Brandung bei nordwestlichen bis nordöstlichen Winden an diesen Stellen sein kann, bezeugen die nach stürmischem Wetter massenhaft „abgeschorenen “ Lanice-Röhren, die dann oft einen breiten Spülsaum am Strand bilden. Bemerkenswert ist, daß während der Monate Januar bis März 1951, bei besonders günstigen Niedrigwasserständen, keine Röhren mit Fransenbüscheln oder Stockwerkbildungen beobachtet werden konnten, dafür aber lagen zahlreiche Wohnröhren im Angespül. Die im Herbst beobachtete Etagenbildung stammt aus der Zeit der ruhigeren Sommermonate, in denen sich die Sedimente einigermaßen stetig absetgen konnten. Die stärkeren Wasserbewegungen in den Wintermonaten hemmen den gleichmäßigen Bau 
der Bäumchen, und durch den starken Wellenschlag wird das Polster abgetragen, was im Winter 1950/51 mindestens um den Betrag der Höhe der gesamten Stockwerke (vgl. Abb. 4) erfolgt sein muß.

\section{E. Auswertungsmöglichkeiten der Beobachtungsergebnisse}

Die Beobachtungen am Wohnröhrenbau von Lanice conchilega, insbesondere die Stockwerkbildung der Fransenbüschel, lassen sich nach zwei Richtungen hin auswerten:

1. Mit Hilfe der Übersandung kann bei Aquariumsversuchen zum Studium des Röhrenbaues die Zeit, in der ein Wurm die Röhre und das Bäumchen herstellt, festgelegt und die Bauweise jederzeit demonstriert werden. WATSON (1890) hatte bei seinen Untersuchungen zwei Wochen lange, ständige Beobachtungen notwendig, bis sich ihm eine günstige Gelegenheit bot. Erwähnt sei, daß die Methode, auf die Linke (1951) bei Aquariumsbeobachtungen an Sabellaria spinulosa hinweist, mit verschieden gefärbten Sand gebänderte Sandkorallenbauten zu erhalten, auch bei Lanice zu buntstöckigen Wohnröhren führt.

2. Bei Untersuchungen über Sandverfrachtungen und -umlagerungen in den sich an das Eulitoral seewärts anschließenden, tieferen Gewässern kann der Röhrenbau und die Etagenbildung wertvolle Aufschlüsse und Hinweise geben, wobei das Baumaterial und die Abstände der einzelnen Fransenkronen Anhaltspunkte für die Zeitfolgen und die Schichtdicken der verschiedenen Sedimentationen und Sandverdriftungen liefern.

So konnten in den Bodengreiferproben und im Magen- und Darminhalt von Schollen aus der Deutschen Bucht, besonders für die Stationen westlich von Amrum, Lanice-Röhren gefunden werden, die nach den verschiedenen Zonen des Baumaterials der einzelnen Röhrenstücke und den Stockwerkbildungen darauf schließen lassen, daß der Boden in diesem Gebiet dauernden Sandumlagerungen unterworfen ist. Wieweit diese Tatsache sich in der Besiedelung mit anderen Bodentieren wiederspiegelt, wird in einer gesonderten Veröffentlichung eingehender behandelt.

\section{F. Zusammenfassung}

Bei ausgedehnten, dichten Polstersiedlungen von Lanice conchilega am Sylter Ellenbogen-Nordstrand wurde beobachtet, daß die meisten Röhren etagenförmige Fransenkronen zeigten. Diese Beobachtung regte zu Untersuchungen über den Wohnröhrenbau an.

Die Experimente und Einzelbeobachtungen im Aquarium ergaben:

1. Die auf dem oberen Röhrenende stehenden Fransen (das Lanice„Bäumchen“), dienen dem Wurm als Auffangvorrichtung für Nahrung in Form eines Stellnetzes und werden außerdem wie Angelruten benutgt, von denen aus das Tier mit seinen lang-ausdehnbaren Tentakeln den Boden abweidet (Bestätigung der Annahme Watsons).

2. Die Tentakeltätigkeit und die Kotausscheidung bewirken im Aquarium 
die Aufschüttung eines Kegels um das obere, aus dem Boden ragende Röhrenende.

3. Sandüberschüttungen veranlassen den Wurm, die Röhre nach oben zu verlängern, wobei jedesmal eine neue Fransenkrone auf das Röhrenende gesetst wird.

4. Die Höhe der Lanice-Bäumchen ist abhängig von der zur Verfügung stehenden Nahrungsmenge, der mehr oder weniger reichen Bodentrübe in den untersten Wasserschichten unmittelbar über der Sedimentoberfläche; bei guten Ernährungsbedingungen werden hohe (um $20 \mathrm{~mm}$ ) Bäumchen gebaut, bei schlechten sitgen die Ästchen dicht über dem Boden.

5. Im Innern des Bodens kann der Wurm nur so bauen, daß er das Sediment beiseite drückt und gleichzeitig den Röhrenschaft herstellt, indem die Bodenbestandteile auf dem ausgeschiedenen Schleimmantel, der Grundschicht der Röhre festkitten.

6. Die nach neueren Arbeiten von KöNIg (1949) und SeIlacher (1951) beobachtete U-Form der Wohnröhre bei Lanice wurde auf ihre Notwendigkeit hin untersucht und im Experiment nachgewiesen, daß die Anlage einer U-Röhre von besonderen Umständen abhängig ist.

Beobachtungen am natürlichen Standort zeigten, daß nach Bodengreiferuntersuchungen Lanice im Ostteil der Deutschen Bucht bis $50 \mathrm{~m}$ Tiefe in reinbis schlicksandigen Böden vorkommt.

In der Gezeitenzone siedelt Lanice einzeln, in Flecken, in Rasen und Polstern. Dabei konnte eine Abhängigkeit der Besiedelung einzelner Standorte von den physikalischen Eigenschaften des Untergrundes festgestellt werden. Die Bestände werden mit zunehmender Korngröße dichter und entwickeln sich an den Stellen, an denen auf grobsandigem Grund durch bèsondere Verhältnisse die Ernährungsbedingungen günstig sind, zu den riffartigen, extrem dichten Lanice-Polstern, wie sie am Nordstrand des Ellenbogens/Sylt unter der MTnW-Linie angetroffen werden.

Die bei den Versuchen angewandte Methode der Sandüberschüttungen bietet ein gutes Hilfsmittel zur Beobachtung und Demonstration des Röhrenund Bäumchenbaus von Lanice im Aquarium. Die Stodkwerkbildung der Fransenkronen im natürlichen Standort kann bei Untersuchungen über Sedimentverfrachtungen und -umlagerungen in tieferem Wasser wertvolle Hinweise und Aufschlüsse geben.

\section{G. Lit e r a tur}

Caspers, H., Die Bodenfauna der Helgoländer Tiefen Rinne. - Helg. Wiss. Meeresunters. 2, 1938.

- Die Lebensgemeinschaften der Helgoländer Austernbank. - Ebenda 3, 1950.

Eales, N. B., The littoral Fauna of Great Britain. - Cambridge, 1950.

Ehlers, E., Beiträge zur Kenntnis der Vertikalverbreitung der Borstenwürmer im Meere. Z. wiss. Zool. 25, 1875.

Fauvel, P., Polychetes sedentaires i. Faune de France 16, Paris, 1927.

Hagmeier, A., Eine Fluktuation von Mactra (Spisula) subtruncata da Costa an der ostfriesischen Küste. - Ber. Deutsch. Wiss. Komm. f. Meeresforschg. N. F, 5, 1930.

- Die Nahrung der Meerestiere III-IV, - in Handb. d. Seefisch. Nord-Europas. 1. Heft 5b, 1951.

- und R. Kändler, Neue Untersuchungen im nordfriesischen Wattenmeer und auf den fiskalischen Austernbänken. - Helg. Wiss. Meeresunters., N. F. 16, 1927. 
König, D., Vergleichende Bestandsaufnahmen an bodenbewohnenden Watt-Tieren in Gebiet des Sicherungsdammes vor dem Friedrichskoog (Süderdithmarschen) in den Jahren 1935 bis 1939. - -Westküste ${ }^{\circ}$, Kriegsheft 1943.

- Uber die Wohnwerse einiger im Boden lebender Tiere des Wattenmeeres. - Verh. d. Deutsch. Zoologen 1948, Leipzig 1949.

Linke, O., Die Biota des Jadebusenwattes. - Helg. Wiss. Meeresunters. 1, 1939.

- Neue Beobachtungen über Sandkorallenriffe in der Nordsee. - Natur und Volk, 81, 3/4, 1951.

McIntosh, A Monograph of the British Marine Annelids. - 4, London, 1922.

Seilacher, A., Der Röhrenbau von Lanice conchilega (Polychaeta). - Sendkenbergiana, 32, $1 / 4,1951$.

Watson, A. T., The tube - building Habits of Terebella littoralis. - Journ. of the Royal Microscopical Society, 1890.

- A case of Apparent Intelligence exhibited by a marine Tube - building Worm, Terebella conchilega. - Ebenda 1916.

Wesenberg-Lund, E., The Zoology of Iceland, 2, Teil 19: Polychaeta. - Copenhagen und Reykjavik, 1951.

Wilson, D.P., The relation of the substratum to the metamorphosis of Ophelia larvae. Journ. Mar. Biol. Ass. Plymouth, 27, 1948.

- Life of the shore and shallow Sea. - London, 1950.

Wohlenberg, E., Die Wattenmeer-Lebensgemeinschaften im Königshafen von Sylt. Helg. Wiss. Meeresunters, 1, 1937.

Yonge, C. M., The Sea Shore. - London, 1949.

Ziegelmeier, E., Zur Klärung der Cordelringbildung bei Schollen. - Fischereiwelt, 3, Heft 3, 1951. 